\title{
Specificity of formation of creative activity skills in studio theatre: competency-based approach
}

\author{
Natalia B. Buyanova ${ }^{1 *}$, Alexey P. Efremenko ${ }^{2}$, Lyubov E. Shevchuk ${ }^{3}$, Olga G. Orekhova ${ }^{1}$, \\ and Stanislav N. Mikhaylov ${ }^{4}$ \\ ${ }^{1}$ Moscow State Institute of Music named after A.G. Schnittke, Choral Conducting Department, \\ Moscow, Russia \\ ${ }^{2}$ Russian State Social University, Faculty of Arts, Moscow, Russia \\ ${ }^{3}$ Moscow State Pedagogical University, Institute of Fine Arts, Department of Methodology and \\ Technologies of Pedagogy of Music Education, Moscow, Russia \\ ${ }^{4}$ The Academic Music School at the Moscow State Conservatory P.I. Tchaikovsky, Orchestral String \\ Department, Moscow, Russia
}

\begin{abstract}
This article presents the experimental results of analysis of efficiency of teaching methods aimed at formation of creative activity skills of future actors during training in studio theatre. In the course of the research, psychological and pedagogical theories of formation of creative activity skills were studied; on the basis of experiments, the efficiency of specially developed methods aimed at formation of creative activity skills was proved. These are the methods of development of imagination and thinking, actor abilities, expansion of emotional sphere, worldview and experience of actors in the area of perception of arts pieces, and scenic practice in working on role and stage performance. The authors have systematized the skills of theatrical performance and highlighted as the most meaningful the skills of artistry, scenic mastery, creation of new images or actions, application of various means of stage arts, preparation and performance of stage pieces of various genres, execution of professional functions of actor, director, scriptwriter. Practical value of the work is in obtaining of new scientific data as well as formulation of recommendations regarding the process of formation and development of creative activity skills of students during training in studio theatre.
\end{abstract}

Keywords: creative skills, creative activity, theatrical art, acting technique, methods of teaching.

\section{Introduction}

Specificity of creative activity is comprised of creation of cardinally new and unique in the field of science, arts in accordance with human's demands: new inventions and discoveries, pieces of music, arts, theatrical and other works. Subjective significance of creativity is that the creative activity becomes an act of self-expression and realization of creative potential of a person.

\footnotetext{
${ }^{*}$ Corresponding author: dirigent.nb@mail.ru
} 
The issue of formation of creative skills and development of creative abilities up till now attracts the attention of philosophers, psychologists, and pedagogists. L.S. Vygotsky considered that creativity was a required condition of human existence, activity on creation of qualitatively new, not existing previously in terms of conception and material embodiment [1]. Herewith, the new could be a thing of ambient world or mental construction existing only in consciousness of creator [1].

Foreign researchers [2-4] interpret the term creativity as ability, readiness and commitment of an individual to creation of cardinally new concepts as well as to solution of problems occurring inside static systems. Creativity as a complex property of a personality is characteristic of inventors, researchers, people of art [2]. They are able to overcome stereotypes and patterns. Maslow believes that creativity is an intrinsic property of each personality, which is exposed in practical activity as a property of productive intensity of individual consciousness [3]. Guilford interrelates ability to creative activity with divergent thinking, which allows to detect new bonds between the system elements and creation of original combinations of these elements [4]. James interrelates creativity with peculiar psychic properties of a person [5]. Therefore, the system approach is the most efficient upon working with young actors.

In foreign publications, the issue of development of creative skills and abilities attracts great attention $[6,7]$. This issue is solved by means of active creative and research activity $[8,9]$, esthetic and educational activity $[10,11]$. In addition, the methods and techniques of development of creative abilities are being developed $[12,13]$; however, the process of formation of creative activity skills of actors has been studied insufficiently.

In information society, the creative activity skills are being weakly developed. In particular, young people are far from creative activities, who form their capacities under conditions of massive information flows and rapid change of events, which decrease ability to critically assess each phenomenon and to make independent decision of creative tasks. Therefore, during professional training of specialists of creative activity, such as musicians, actors, dancers, etc., special attention should be paid to formation of creative activity skills. They comprise the basis of professional competency of various people of art.

\section{Methods}

Experimental work on formation of creative activity skills was carried out in Benefis studio theatre in Moscow. 20 persons participated in the experiment, 18 to 23 years old, who were in the group trained in the studio from September 2019 to May 2020. The practical work was preceded by analysis of scientific theoretical publications and systematization of creative activity skills of the theater actors.

The actorly creative skills are as follows:

- skills of artistry,

- skills of scenic mastery,

- skills of creation of new images or actions,

- skills of application of various means of scenic art,

- readiness to perform theatric shows of various genres,

- execution of professional functions of actor, director, scriptwriter.

Formation of creative activity skills of future actors requires attention to such thinking and psychic processes, which are being stabilized during this age period. They are comprised of associativity, flexibility, originality, dialectical and systemic thinking, allowing to see the world in a multifaceted holistic way, as well as to determine the regularities of its development by analysis and synthesis. The creative activity skills are related with the properties of experimental thinking; thus, it is primarily required to develop such thinking abilities as imagination and fantasy. 
The main pedagogic task in organization of work of studio theatre and creative manifestations of the participants is enrichment of experience of young people and creation of conditions for their creative self-realization in practice activity [14]. The basic pedagogic principle upon working with actors should be comprised of the principle of teaching in practical activity, self-actualization and self-realization of personality during execution of assignments. In the studio theatre, such actions can be presented by problematic creative assignments, trainings, as well as creation and performance of scenic image during rehearsals and public performances.

\section{Results}

The program of diagnostics of formation level of creative activity skills at experimental stage was based on the method of problematic assignment, comprised of independent work on role in a new play, including all stages from the first conversance with the play to mastering peculiar features of personage [15].

The roles were distributed among the participants in the experiment: young men and girls of key and spare team (by 10 persons), the task was to create image at several steps. The diagnostics allowed to reveal problems at such steps of working on role as determination of logics of the role actions based on estimation of facts and events; clarification of circumstances of happening and details of role; reflection of external speech and plasticity features of the role, as well as creation of holistic image at public performances.

In general, the assignments were carried out by the studio actors at medium and low level. Therefore, it was decided to create special organizational conditions for formation of skills of theatrical performing activity of future actors during training in Benefis studio theater. The studio teachers applied such methods to work on role as analysis, comparison, contrast, deduction and induction, as well as methods of demonstration and rehearsal. The dominating forms were role and thematic games, improvisation, scenic practice. Systematic and targeted individual classes based on productive activity, i.e., stepwise and detailed creation of scenic image, resulted in optimum organizational and creative conditions for efficient formation of creative activity skills in the field of theatric art.

Specificity of formation of the considered skills was based on creative environment, which would allow to apply the already existing skills and habits and to acquire new ones. In Benefis studio theatre, creative environment was arranged due to regular contact with pieces of art with subsequent exchange of opinions and impressions, studying pieces of art in the course of special disciplines, searching and improvisational approach to theatric performing activity, collective discussions concerning all stages of preparation of performances. The studio actors analyzed jointly the play events and their circumstances, features of roles and their development, exchanged ideas, thus coming to the truth during hot disputes.

One of the most important conditions to achieve target was the use of combination of the methods of theatrical pedagogy, based on composing, imagination, and improvisation as a single basis of multimethodological approach. Herewith, the composing method included such forms of education as conversation, storytelling, discussion; imagination was implemented in the form of creative assignments, role and thematic games, and improvisation in the forms of scene study, sketches, staging.

\section{Discussion}

Skills of creative, actorly performing activity were formed and developed during active scenic practice; hence, creation of conditions for scenic practical activity also promoted improvement of efficiency of training young people in studio theatre. Systematic and targeted 
rehearsals included stepwise and detailed workout of role, and regular classes of acting mastery, speech development, choreography, and music assisted studio actors in capturing fine details of scenic image and embodying them in their acting. The stage practice in Benefis Studio was aimed at establishment of acting mastery and oratorical skills, development of personal emotional sphere, acquisition of speech, creative, and communication skills, as well as preparation to work in front of spectators and camera. In addition, only in scenic practice an actor is immersed into direct process and starts control his creative actions, which are transformed into skills due to regular training.

After completion of forming stage of experimental work, aiming at determination of efficiency of created organizational, pedagogical and creative conditions, reference estimation was carried out of the formation level of skills of actorly activity, as well as comparison of indices of experimental (key team) and reference (spare team) groups. The assignment to determine the logics of role actions and estimation of facts and events was performed by the participants of the experimental group at significantly higher level in comparison with the reference group. Moreover, other assignments for the actors of spare team were also performed at medium and lower levels.

\section{Conclusion}

The efficiency of formation of creative activity skills of actors is stipulated by the following features:

- domination among the methods and forms of work of studio actors on roles of role playing and thematic games, improvisations, trainings, as well as actorly and creative activity in whole starting from music classes to regular scenic practice;

- creation of actorly esthetic environment in studio theatre, atmosphere of emotional wellbeing and success, filling of studies with significant for young actors content and ideas close to their hearts;

- application of various methods and techniques, individualized in accordance with age and personal properties of each studio actor;

- scenic practice as a regular and targeted form of work of studio actors on creation and performance of scenic image.

The program of creative development and education of Benefis Studio includes gaming and psychophysical imagination trainings, deliverance, articulation, acting techniques, breathing exercises, rhythmic and speech exercises, etc. Due to regular gaming and psychophysical trainings, the emotional sphere of actors is being developed, as well as speech and articulation, their bodies become plastic. The skills of creative activity require absolute freedom and mastery of all the expressive means of scenic art necessary for an actor, which are mastered in the course of regular exercises for liberation, emotionality, development of attention, imagination, fantasy, diction and articulation, memory, concentration and improvisation.

\section{References}

1. L.S. Vygotsky, Psihologiya iskusstva [The psychology of art] (Feniks, Rostov-on-Don, 1998)

2. J.S. Renzulli, S.M. Reis, The three-ring conception of giftedness: a developmental approach for promoting creative productivity in young people, in APA Handbook of giftedness and talent, 185-199 (American Psychological Association, New York, 2018) 
3. A.H. Maslow, Motivatsiya i lichnost [Motivation and personality] (Piter, Saint Petersburg, 2014)

4. J. Guilford, Tri storony intellekta [Three dimension of intelligence] (Progress, Moscow, 1965)

5. W. James, Psihologiya [Psychology] (Pedagogika, Moscow, 1991)

6. L.V. Bogdanova, Development of creativity as the basic competence in the postindustrial digital society, in Culture and Education: Social Transformations and Multicultural Communication. Proceedings of the Middle-Term Conference RC04 Sociology of Education International Sociological Association (ISA), Russian University of Friendship of Nations, Moscow, Russia, 405-411 (2019)

7. V.V. Lutay, Development of creative abilities of students in the conditions of introduction of the Federal state educational system. Academy of Creativity Development “Art-Talent” (2020). Accessed on: December 10, 2020. [Online]. Available: https://www.art-talant.org/publikacii/22864-development-of-creativeabilities-of-students-in-the-conditions-of-introduction-of-the-federal-state-educationalsystem

8. M.Yu. Shusharina, E.M. Miroshnichenko, Municipal Education: Innovation and Experiment, 4, 70-79 (2013)

9. G. Shamatova, Development of creative skills through practical tasks in chemistry, in The Proceedings of the Fourth International Conference on development of pedagogical science in Eurasia, 1 March 2015, Vienna, Austria, 117-121 (2015)

10. B. Gurkan, S. Dolapcioglu, Egitim Ve Bilim-Education and Science, 45/202, 51-77 (2020). http://doi.org/10.15390/EB.2020.8474

11. Z. Rasulova, Theoretical \& Applied Science, 12(80), 624-627 (2019). https://dx.doi.org/10.15863/TAS.2019.12.80.118

12. G.N. Ibragimova, Methods and technologies and technologies of the development of students' creative abilities, in Proceedings of 13th International Conference "Lifelong learning: continuous education for sustainable development", Pushkin LSU, Saint Petersburg, Russia, 269-271 (2015)

13. M.V. Pereverzeva, M.L. Kats, V.A. Ovsyannikova, S.S. Aksenova, N.S. Yushchenko, Universal Journal of Educational Research, 8(7), 2766-2771 (2020). http://doi.org/10.13189/ujer.2020.080703

14. E.A. Medvedeva, Eurasian Union of Scientists, 11(2(4)), 28-30 (2015)

15. L.L. Alekseeva, Humanity space. International almanac, 4(2), 133-140 (2015) 